\title{
Comparison of Mental Health of Female Students with Early, Late, and Normal Menarche in Isfahan, Iran
}

\section{Elham Irannezhad $^{1, *}$ (iD), Mohammad Soltanizadeh ${ }^{2}$}

${ }^{I}$ PhD Candidate, Department of Psychology, Isfahan (Khorasgan) Branch, Islamic Azad University, Isfahan, Iran

2 Assistant Professor, Department of Psychology, Payam Noor University (PNU), Iran

* Corresponding Author: Elham Irannezhad, Department of Psychology, Isfahan (Khorasgan) Branch, Islamic Azad University, Isfahan, Iran. Email: elhamIrannegad@yahoo.com

Received: 09.10.2020

Accepted: 28.01.2021

\section{How to Cite this Article:}

Irannezhad E, Soltanizadeh M. Comparison of Mental Health of Female Students with Early, Late, and Normal Menarche in Isfahan, Iran. Avicenna J Clin Med. 2021; 27(4): 253-260. DOI: $10.29252 / \mathrm{ajcm} .27 .4 .253$

\section{Abstract}

Background and Objective: The changes that occur in the female body with the onset of menstruation affect the psychological components, including mental health. This study aimed to compare the mental health of adolescent females with early, late, and normal menarche.

Materials and Methods: This descriptive study was conducted based on a causal-comparative design. The statistical population included 9- to 17-yearold female students in Isfahan, Iran, who were selected through multistage random cluster sampling. The sample size was determined at 56, 37, and 43 cases in the group of students with normal, early, and late menarche, respectively. The data were collected using the Pediatric Symptom Checklist for school-aged children (age range: 3-18 years) (Jelink, Murphy, and Burns, 1986). Following that, the collected data were analyzed using SPSS software (version 25) through a covariance test.

Results: According to the results, no significant difference was observed between the two groups of female students with normal and early menarche regarding mental health and its subscales. However, the adolescent females with late menarche had better mental health, compared to those with early and normal menarche $(\mathrm{P}<0.01)$.

Conclusion: Based on the results, it seems that the timing of the onset of menstruation affects mental health. The late menarche is associated with fewer mental health problems.

Keywords: Menarche, Mental Health, Students 
dof: $10.29252 / \mathrm{ajcm} \cdot 27.4 .253$

\title{
مقايسه سلامت روان دانش آموزان دختر داراى قاعدكى عادى، زودرس و ديررس در شهر اصفهان
}

\author{
الهام ايراننزادا:" iD ، محمد سلطانىزاده \\ ' انشجوى دوره دكترى، كروه روانشناسى، واحد اصفهان (خوراسكان)، دانشعاه آزاد اسلامى، اصفهان، ايران

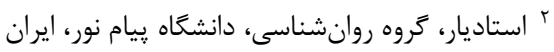 \\ * نويسنده مسئول: الههام ايراننزاد، كروه روانشناسى، واحد اصفهان (خوراسعان)، دانشگاه آزاد اسلامى، اصفهان، ايران. \\ ايميل: elhamIrannegad@yahoo.com
}

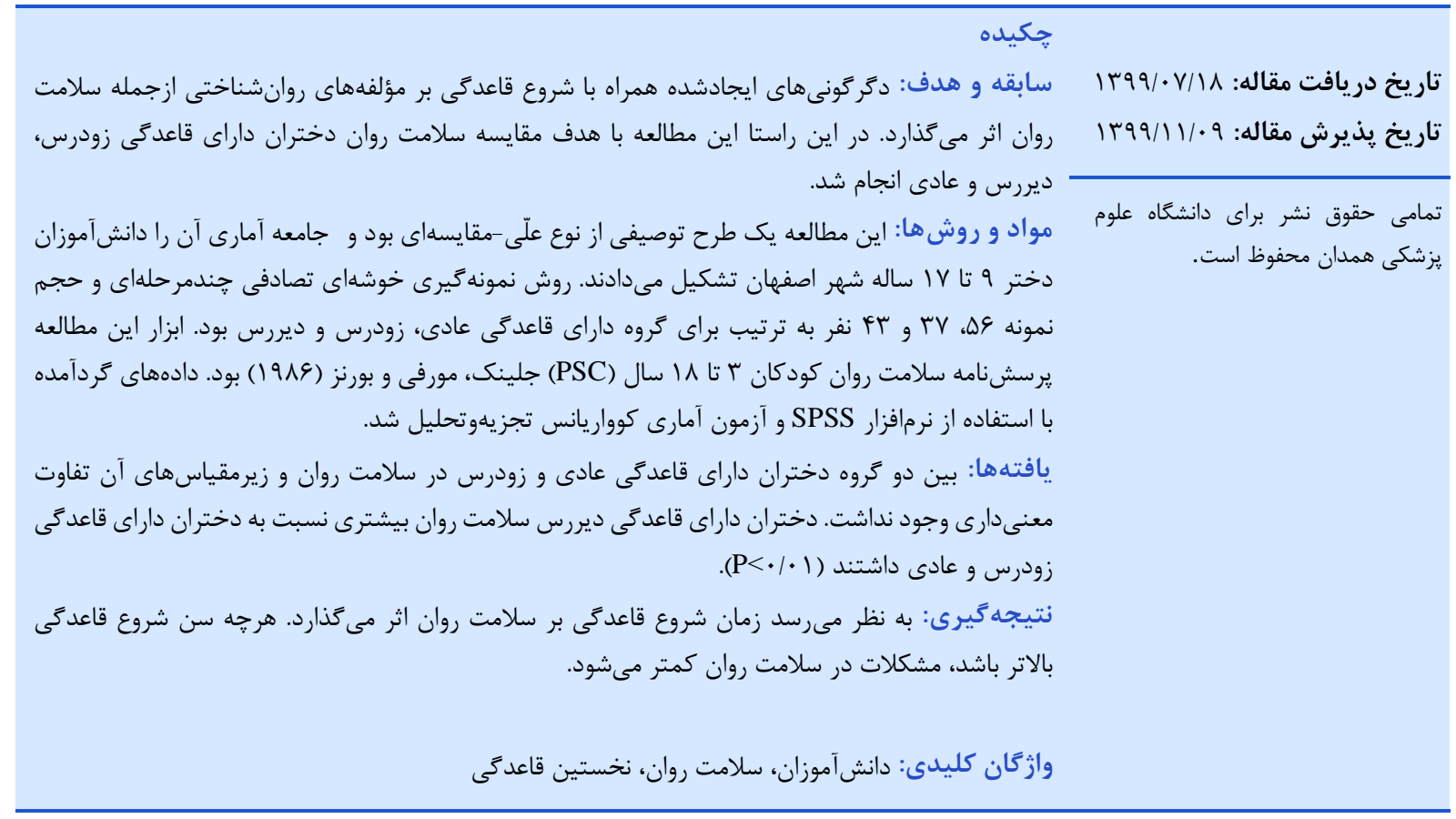

مقلدمه

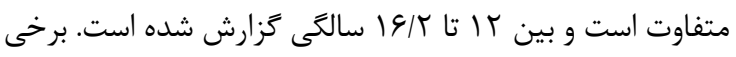

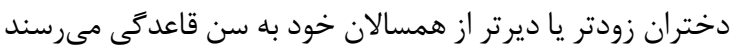

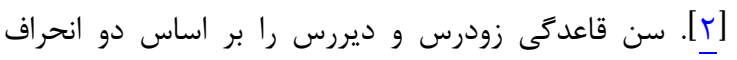

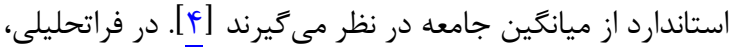
ميانكين سن نخستين قاعدگى در ايران

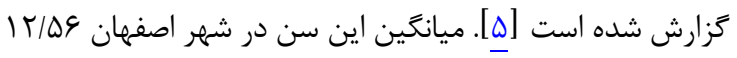

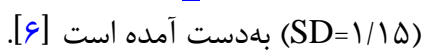

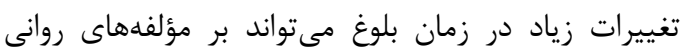

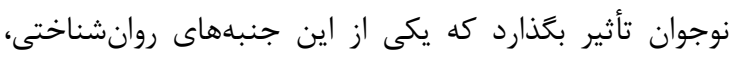

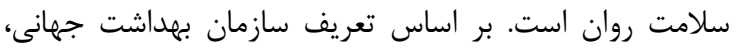

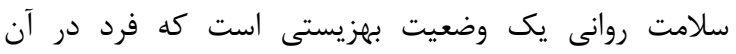

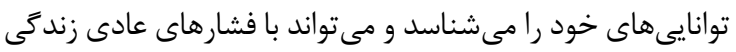

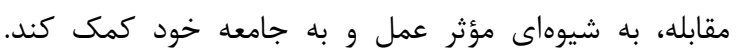

بلوغ دورهاى از رشد است كه تغييرات هورمونى، روانى،

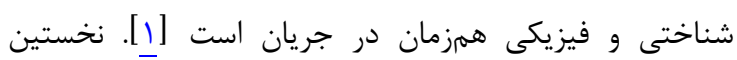

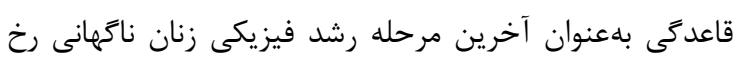

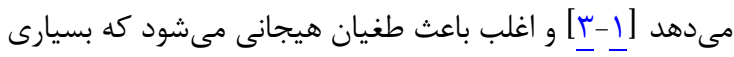

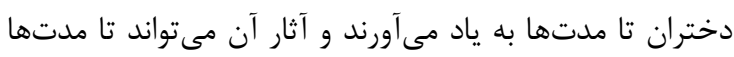
برجاى بماند و نكرش دختران به قاعدگىى، رفتار سلامتى و تصوير

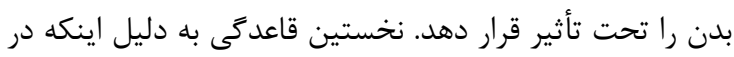

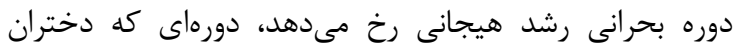

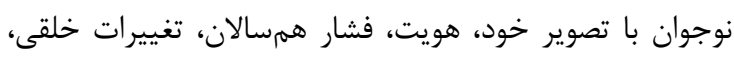

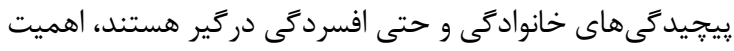
زيادى مى يابد. افسردكى، اضطراب و ناتوانى تمركز على علائم روانى

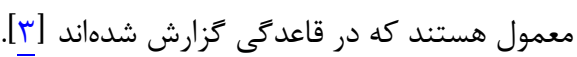
زمان نخستين قاعدگى در بين كشورها و اقوام گوناگون دنيا درديا 
مقايسه سلامت روان دختران داراى قاعدگى زودرس، ديررس و

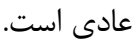

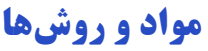

اين مطالعه يك طرح توصيفى از نوع علّى-مقايسهاى بود.

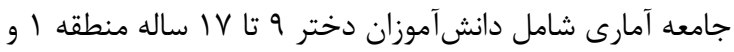

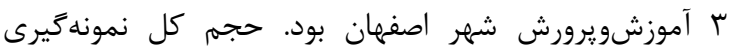

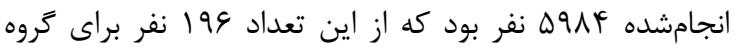

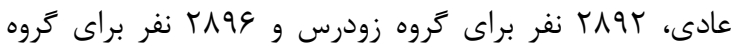

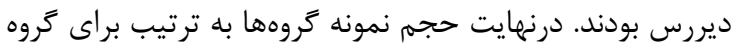

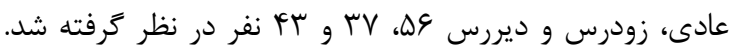

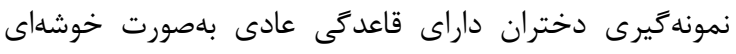

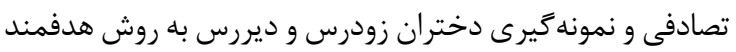

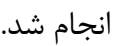

براى گروه دختران داراى قاعدگى عادى دو ناحيه ا و ومّ

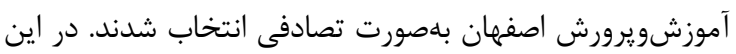

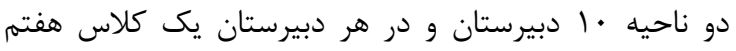

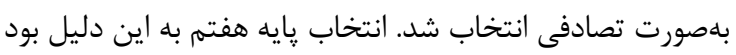

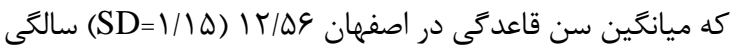

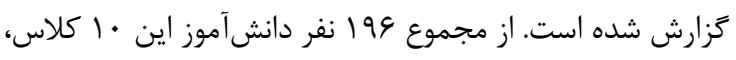

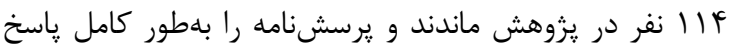

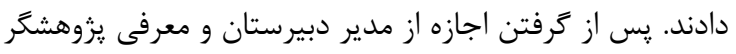

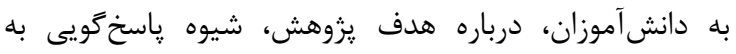

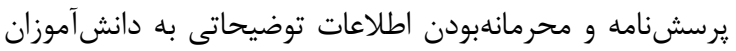

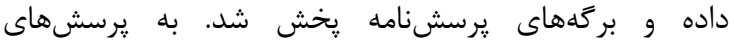

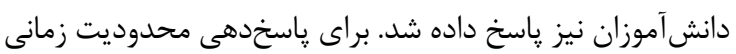

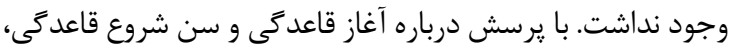
وه نفر با سن قاعدگى طبيعى انتخاب شدند

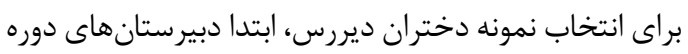

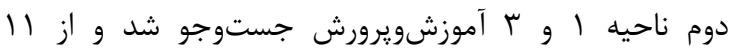
مدرسهاى كه بلهطور تصادفى انتخاب شدند و براى انجام تحقيق

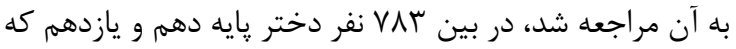

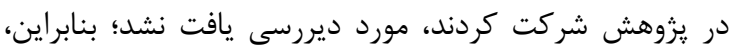

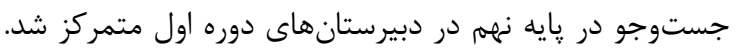

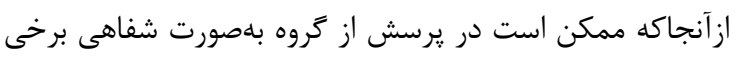

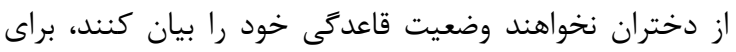

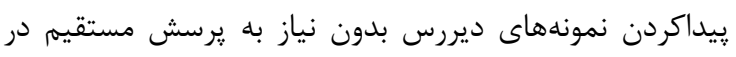

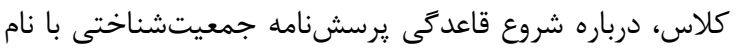

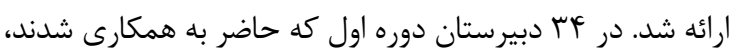

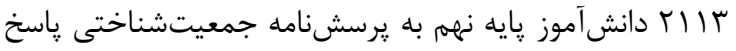

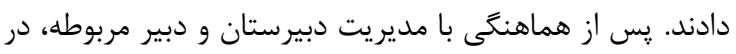

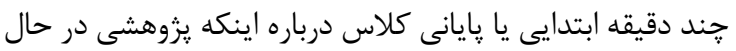

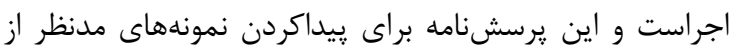

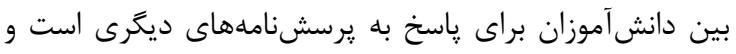

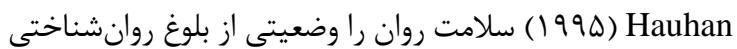

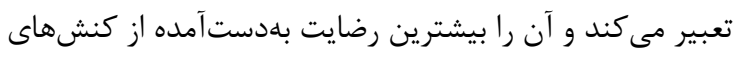

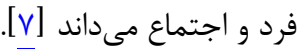

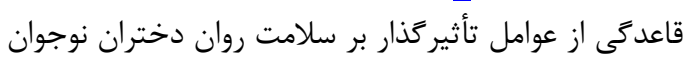

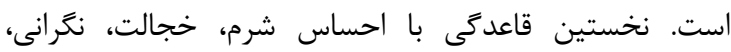

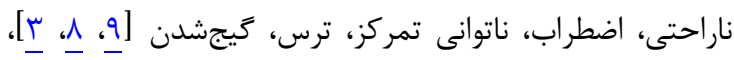

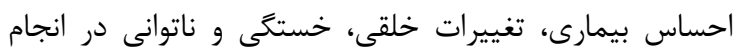

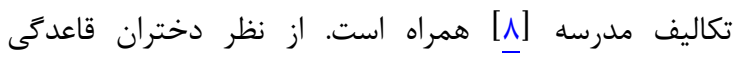

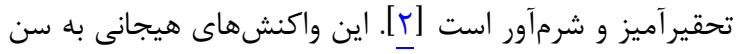

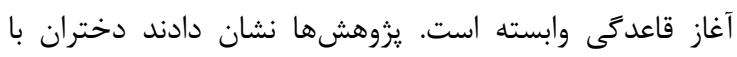
قاعدىى زودرس احساس افسردىى، اضطراب، خشم، نشخرانى،

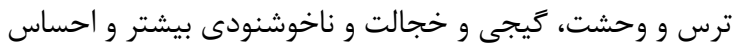

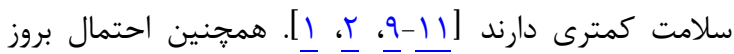

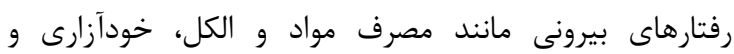

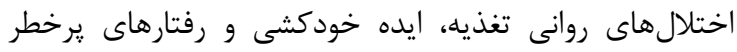

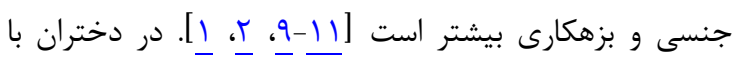

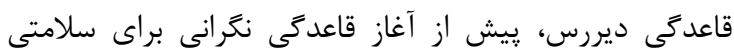

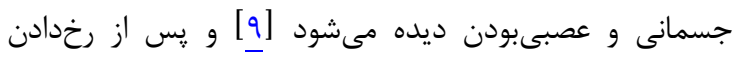

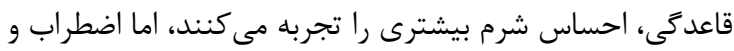

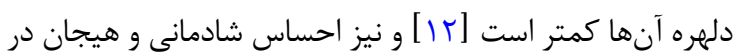

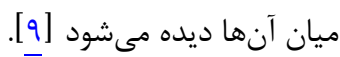

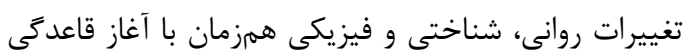
نتايج فردى و اجتماعى به همراه دارد. اين تغييرات در خئى خانواده

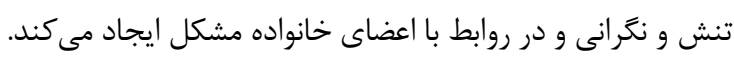

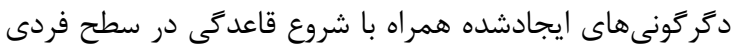

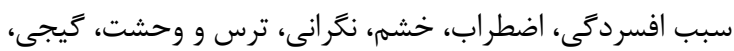

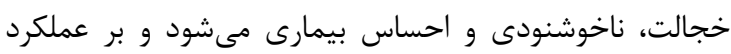

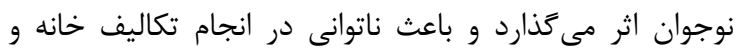

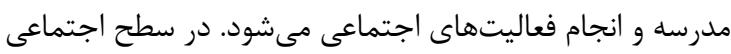

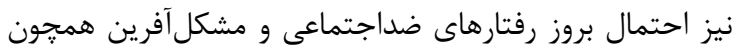

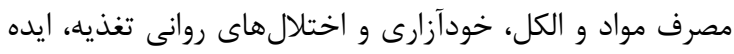

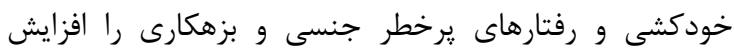

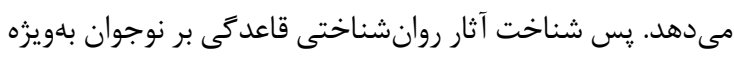

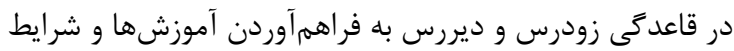

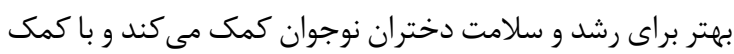

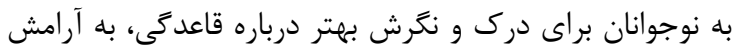
محيط خانه و سلامت اجتماع نيز كمك مى شى دود.

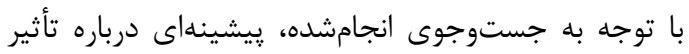

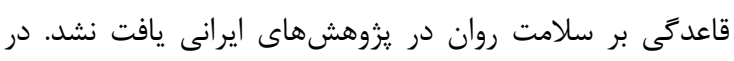

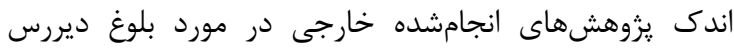

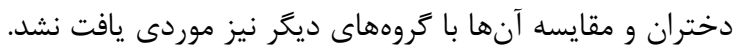

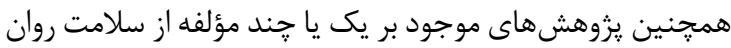

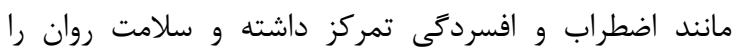
بهطوركلى بررسى نكردهاند. ازاينرو هدف انجام اين مطالعه 
زير ه|• إل سال و براى گروه ديررس بالاى ه/ | | سال بود؛ رضايت

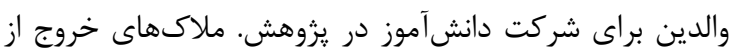

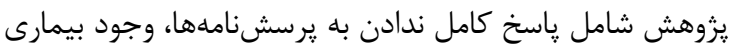

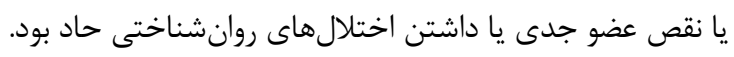
در اين يزوهش براى تجزيهوتحليل دادهها در سطح توصيفى احتئ

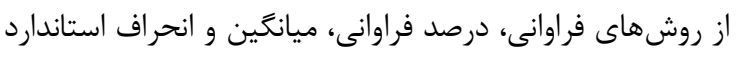

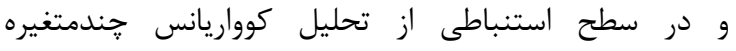
(MANCOVA) سطح معنى دارى ه • • انجام شد. باء ديرى نرم

\section{PSC: برسشنامه سلامت روان كودكان س تا 11 سال}

\section{Pediatric Symptom Chechlist}

و و همكاران (9ellinek

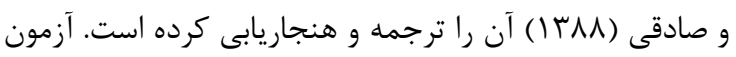

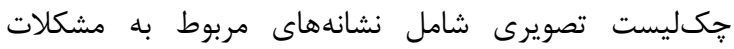

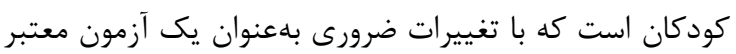

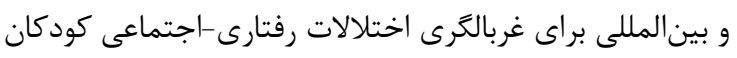

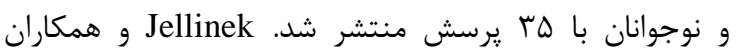

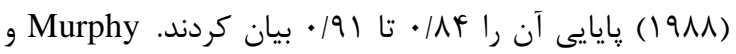

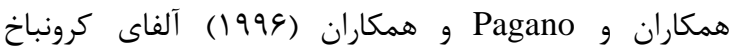

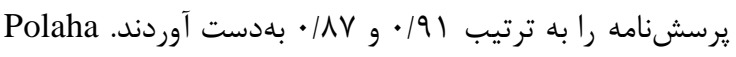

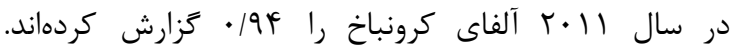

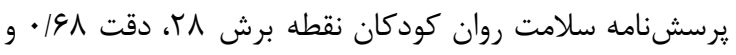

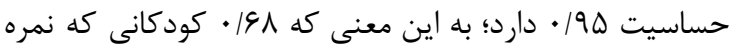
مثبتى در اين يرسشنامه گرفتهاند، توسط متخصصان مان نيز

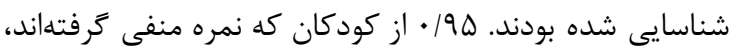
بدون اختلال شناسايى شدند.

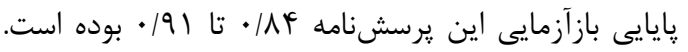

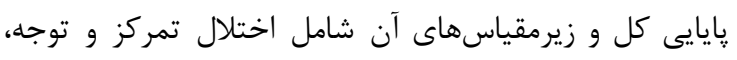
اختلال برونسازى و اختلال درونسازى با استفاده از آلفاى دئي

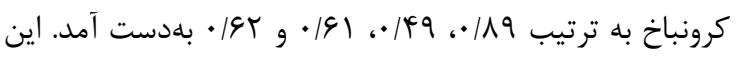

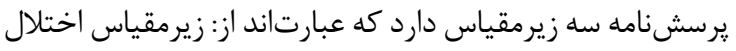

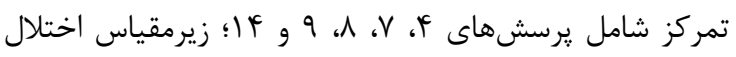

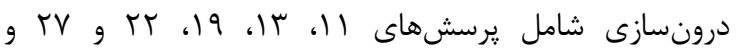

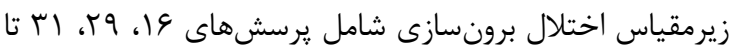

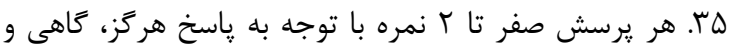

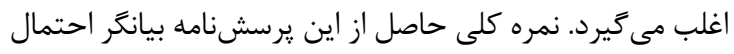

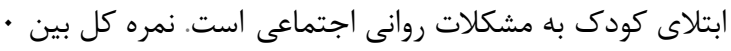

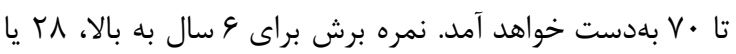

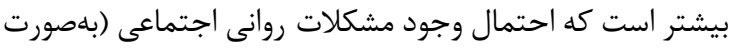

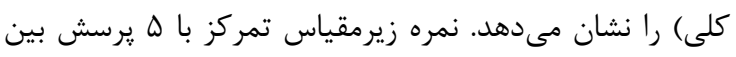

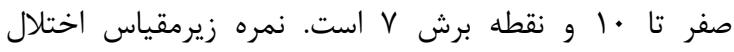

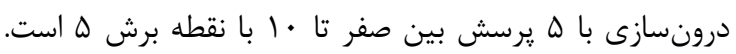

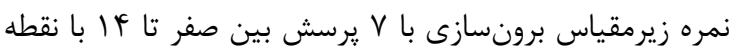

اطلاعات آنها محرمانه باقى مىماند و اينكه مىتوانند در اين يزوهش شركت نكنند و بر گهها را سفيد بازگردانند، توضيحاتى مانى

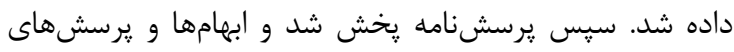

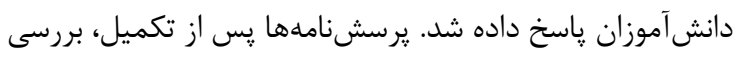

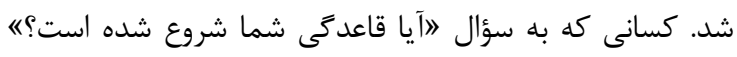

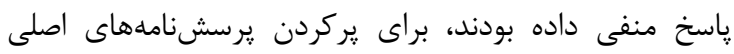
فراخوانده شدند.

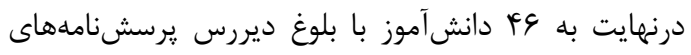

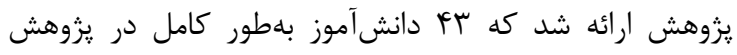

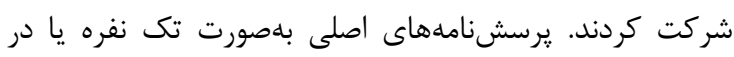

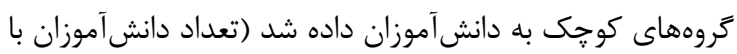

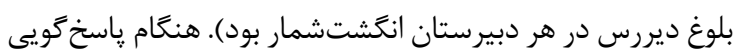

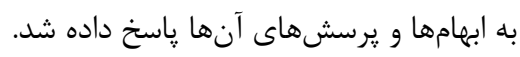

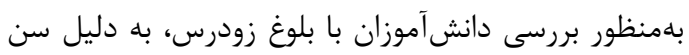

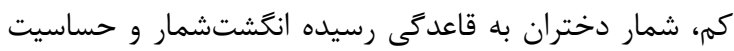

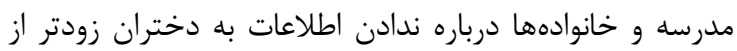

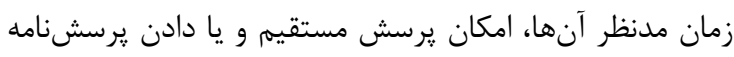

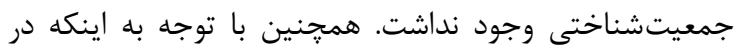

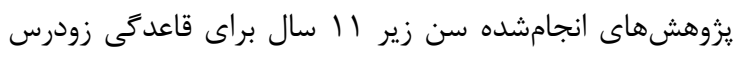

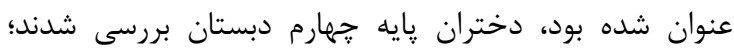

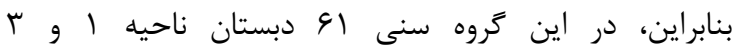
آموزشويرورش اصفهان به جند روش با كمك مديريت دين دبستانها

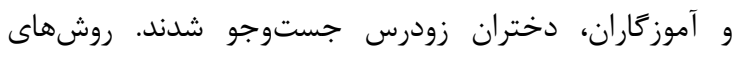

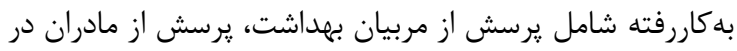

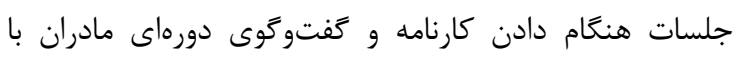

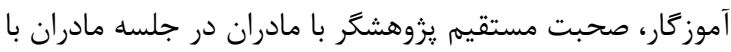

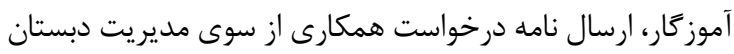

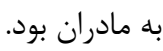
يس از شروع بيمارى كرونا و بستهشدن مدرسهادها كار

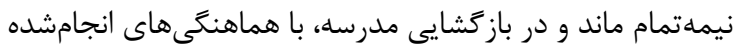

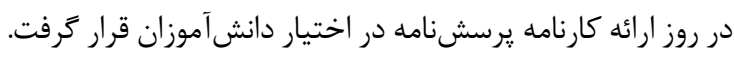

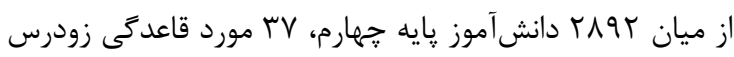
يافت شد. هريك از دختران زودرس ييداشده جداكانه فراخوانده

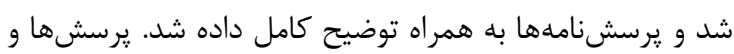

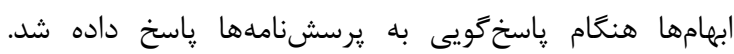
محدوديت زمانى براى ياسخكَّيى وجود نداشت.

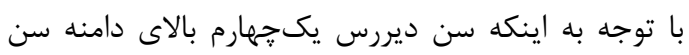

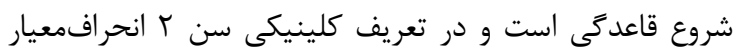

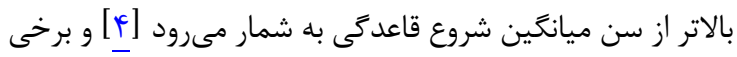

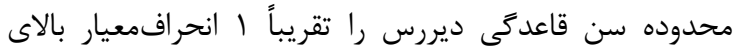

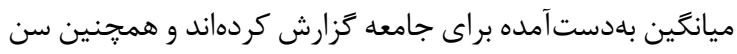

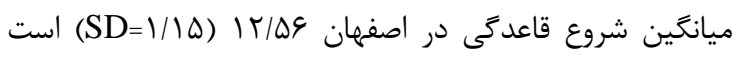

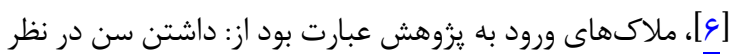

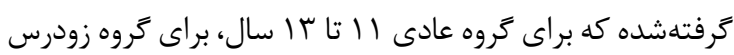




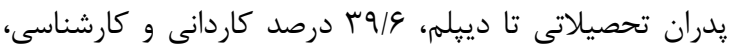

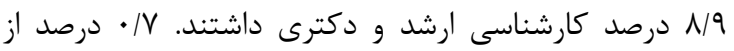

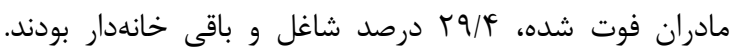

يافته ها

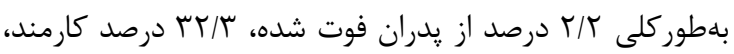

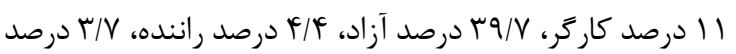

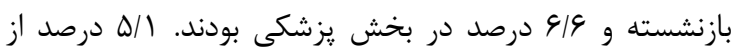

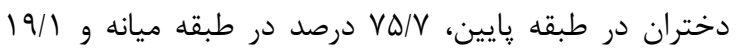

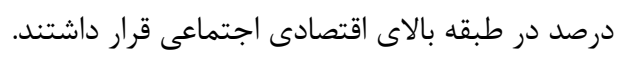

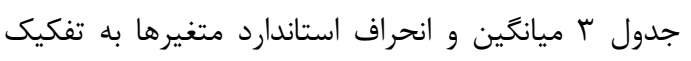

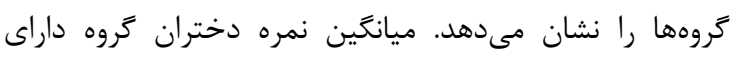

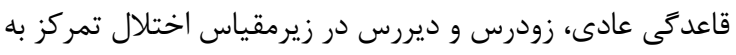
ترتيب F/F

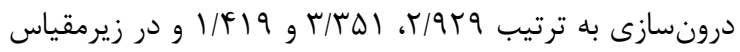

ميانگين و انحراف استاندارد سن دختران و يدران و مادران به تفكيك گروهها در جدول ا آمده است. ميانكين سن دختران

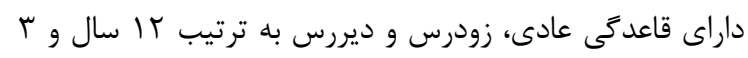

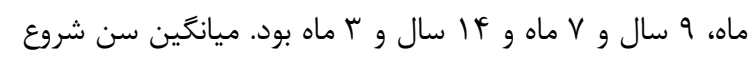

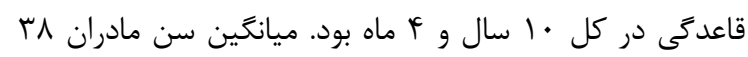

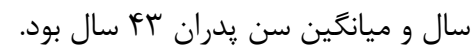

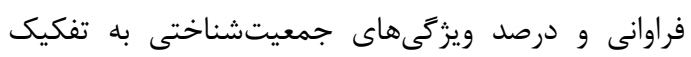

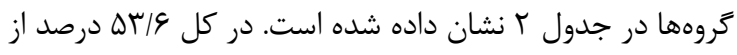

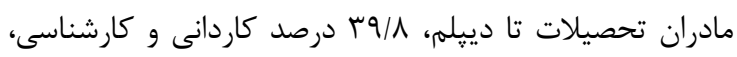

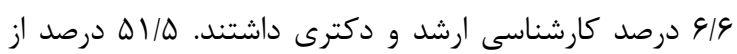

جدول ا: ميانگين و انحراف استاندارد سن دختران، يدران و مادران به تفكيك كروهها

\begin{tabular}{|c|c|c|c|c|c|c|c|c|}
\hline \multicolumn{2}{|c|}{ كل } & \multicolumn{2}{|c|}{ قاعدكى ديررس } & \multicolumn{2}{|c|}{ قاعدَّى زودرس } & \multicolumn{2}{|c|}{ قاعدَّى عادى } & \multirow{2}{*}{ سن (سال) } \\
\hline انحراف معيار & ميانَين & انحراف معيار & ميانغين & انحراف معيار & ميانغين & انحراف معيار & ميانكين & \\
\hline I/AT & $|r / T|$ & $\cdot|4|$ & $\mid r / r$ & $\cdot|\Delta|$ & $9 / V$ & $\cdot \mid f F$ & $1 T / K$ & دختران \\
\hline$\varepsilon / \pi q$ & rی & F/VA & $41 / 19$ & $41 \cdot r$ & ra & $g / 4$. & $r V / F \wedge$ & مادران \\
\hline$V / T V$ & $F r / \cdot r$ & ه/A & $\mid \varphi q 1 \cdot 9$ & N/TG & $r q / \Delta$ & Glar & $F T / 9 D$ & يدران \\
\hline $1 / 49$ & $1 \cdot / 4$ & - & - & $\cdot|\Delta|^{F}$ & N/9 & .190 & $11 / 0$ & سن شروع قاعدكى \\
\hline
\end{tabular}

جدول ץ: فراوانى و درصد ويزَّى هاى جمعيتشناختى به تفكيك گروهها

\begin{tabular}{|c|c|c|c|c|c|c|c|c|c|}
\hline \multicolumn{2}{|c|}{ كل } & \multicolumn{2}{|c|}{ قاعدَّى ديررس } & \multicolumn{2}{|c|}{ قاعدَى زودرس } & \multicolumn{2}{|c|}{ قاعدكى عادى } & & \multirow{2}{*}{ ويز5ى } \\
\hline درصد & فراوانى & درصد & فراوانى & درصد & فراوانى & درصد & فراوانى & & \\
\hline$\Delta r / \varphi$ & Vr & $\Delta r / F$ & r & YN/S & 11 & $\Delta V / T$ & rt & تاديلم & \multirow{3}{*}{ تحصيلات } \\
\hline$r q / \Lambda$ & $\Delta F$ & $r \cdot / r$ & r & $\Delta 1 / \mathbb{R}$ & 19 & $r q / r$ & tr & كاردانى و كارشناسى & \\
\hline $9 / 9$ & 9 & $19 / \pi$ & v & - & - & $r / 9$ & r & ارشد و دكترى & \\
\hline$\Delta / / \Delta$ & v. & $\forall \& / 9$ & $r$. & $\uparrow \Delta / q$ & IV & $\Delta 9$ & 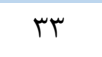 & تا دييلم & \multirow{3}{*}{ تحصيلات } \\
\hline$r q / 9$ & $\Delta F$ & $f \backslash / \Lambda$ & 11 & $\Delta 1 / \mathcal{A}$ & 19 & $r \cdot / r$ & IV & كاردانى و كارشناسى & \\
\hline $1 / 9$ & ir & $11 / 9$ & $\Delta$ & $T / V$ & 1 & $1 \cdot / V$ & 4 & ارشد و دكترى & \\
\hline$\cdot / V$ & 1 & $r / r$ & 1 & - & - & - & - & فوتشده & \multirow{3}{*}{ شادران } \\
\hline$r q / 4$ & r. & $r V / T$ & 19 & Tr/F & ir & $r \mid / F$ & ir & شاغل & \\
\hline $99 / 9$ & 90 & $9 \cdot 10$ & re & $9 V / 9$ & ro & V^/9 & ff & 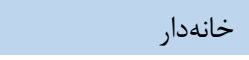 & \\
\hline$T / T$ & r & $F / V$ & r & - & - & $1 / 1$ & 1 & فوتشده يا طلاق & \multirow{9}{*}{ شدران } \\
\hline 11 & 10 & $\mid \psi /$ & 4 & $1 \pi / 0$ & $\Delta$ & $\mathrm{V} / \mathrm{I}$ & f & كارگر & \\
\hline$r \mu / Q$ & rt & $19 / \pi$ & v & rV/A & if & $19 / 9$ & 11 & كارمند & \\
\hline ५ १/V & $\Delta F$ & $r q / \Delta$ & IV & $r \mid / 9$ & $\wedge$ & $\Delta / / \Lambda$ & rq & آزاد (بازارى يا پِيمانكارى) & \\
\hline $9 / 9$ & 9 & $9 / \mu$ & f & $\Lambda / 1$ & r & $r / 9$ & r & يزشكى و بهداشتى & \\
\hline$\Delta / 1$ & v & $r / r$ & 1 & $T / V$ & 1 & $\Lambda / 9$ & $\Delta$ & فرهنگى & \\
\hline $\boldsymbol{k} / \mathbb{q}^{\mathrm{s}}$ & 4 & $F / V$ & r & $1 \cdot 11$ & f & - & - & رانده & \\
\hline$r / V$ & $\Delta$ & $\mathrm{V} / \cdot$ & r & $T / V$ & 1 & $1 / 1$ & 1 & بازنشسته & \\
\hline$r / V$ & $\Delta$ & $r / r$ & 1 & $T / V$ & 1 & $\Delta / \mathcal{F}$ & r & نظامى & \\
\hline$\Delta / 1$ & v & $F / V$ & r & $T / V$ & 1 & $\mathrm{~V} / \mathrm{I}$ & f & קإيين & \multirow{3}{*}{ اقتصادى- } \\
\hline$V \Delta / V$ & I. & $9 \Delta / 1$ & rA & $\wedge 9 / \pi$ & r & $V Q / \cdot$ & fr & ميانه & \\
\hline $19 / 1$ & rq & $r \cdot / r$ & r & N/I & r & $1 V / 9$ & 1. & بالا & \\
\hline
\end{tabular}


جدول بّ: ميانكين و انحراف استاندارد متغيرها به تفكيك كروهها

\begin{tabular}{|c|c|c|c|c|c|c|c|c|c|}
\hline \multicolumn{2}{|c|}{ كل } & \multicolumn{2}{|c|}{ قاعدَى ديررس } & \multicolumn{2}{|c|}{ قاعدَى زودرس } & \multicolumn{2}{|c|}{ قاعدَى عادى } & & \multirow{2}{*}{ متغير ها } \\
\hline انحراف & ميانَين & انحراف & ميانتَين & انحراف & ميانََين & انحراف & ميانغين & & \\
\hline T/DQ9 & $F / \cdot 10$ & T/TEI & T/ANF & T/VAN & $F / V \cdot r$ & $4 / T 11$ & F/FTq & توجه & \multirow{4}{*}{ روان } \\
\hline$r / .91$ & T/D\&9 & 1/Arq & $1 / 419$ & T/TYF & I I & I/ArA & $r / 9 T^{\prime}$ & اختلال درونسازى & \\
\hline$r / \cdot 10$ & r/rqf & $r / \cdot \Lambda r$ & I/TYY & $1 / 99$. & r/FAS & $1 / 9 \Delta \Delta$ & r/AVQ & اختلال برونسازى & \\
\hline$N / \Lambda \cdot 9$ & IV/DTV & $N / q \cdot F$ & $\mid r / \ldots$ & $\mathrm{V} / \cdot 1 \cdot$ & $T \cdot / F T r$ & $V / 911$ & $19 / \wedge V \Delta$ & كل ل & \\
\hline
\end{tabular}

جدول fا: نتيجه تحليل كوواريانس بين گروهى سلامت روان

\begin{tabular}{|c|c|c|c|c|c|c|c|}
\hline Ob.P & eta & $\mathbf{P}$ & $\mathbf{F}$ & ميانتين مجذوررات & مجموع مجذورات & متغير وابسته & منابع تغيير \\
\hline .1998 & .1190 & $\cdot 1 \cdot \cdot 1$ & $1 Y / 9 \cdot \Delta$ & NTD/ITF & $190 \cdot / r 49$ & سلامت روان & \multirow{4}{*}{ عضويت گروهى } \\
\hline - IATD & $\cdot / \cdot v f^{c}$ & .1 .94 & D/THQ & rון & $991 \cdot T V$ & توجه & \\
\hline.$/ 981$ & $\cdot|| r \mid$ & $\cdot 1 \cdot \cdot 1$ & К/৭१^ & rr/qro & $\Leftrightarrow \Delta / \wedge ९ 9$ & اختلال درونسازى & \\
\hline$\cdot / 90$ & $\cdot / 1 \cdot v$ & $\cdot 1 \cdot \cdot 1$ & V/ANF & $r q / \cdot v q$ & $\Delta \Lambda / / \Delta V$ & اختلال برونسازى & \\
\hline$\cdot / \cdot V T$ & $\cdot \cdot \cdot 1$ & $\cdot \operatorname{lqg} 4$ & .119 & $|r /| F q$ & $\mid r / 1 F q$ & سلامت روان & \multirow{4}{*}{ سن یدران } \\
\hline$\cdot|\cdot 1|$ & $\cdot / \cdot r$ & $\cdot 19 \cdot 4$ & $\cdot / T V$ & $1 / V \cdot 1$ & $1 / V \cdot 1$ & توجه & \\
\hline $.1 .9 \mathrm{~V}$ & $\cdot / \cdot \cdot 1$ & .1991 & $\cdot / l \Delta T$ & $\cdot / \Delta \Delta \Delta$ & $\cdot / \Delta \Delta \Delta$ & اختلال درونسازى & \\
\hline$\cdot / r \Delta \Lambda$ & r & .119 & I/VKG & $g / F \cdot r$ & $q / F \cdot F$ & اختلال برونسازى & \\
\hline • / TAT & .1 .19 & . & T/DFT & IET/QIT & IET/DIT & سلامت روان & \multirow{4}{*}{ وضصادى } \\
\hline$\cdot / \cdot \Delta \cdot$ & $\cdot 1 \cdot \cdot 1$ & . /9\& & . H & $.1 \cdot 1 \mathrm{f}$ &.$/ .1 f$ & توجه & \\
\hline$\cdot|T Y|$ &.$/ \cdot 14$ & $\cdot / 4 \cdot \Lambda$ & $1 / 9 \cdot 1$ & D/AGT & D/AGT & اختلال درونسازى & \\
\hline . llfr & $\cdot 1 \cdot \cdot 4$ & • TrVe & $\cdot / \vee \wedge \Lambda$ & $r / 9 \cdot \Lambda$ & $r / 9 \cdot \Lambda$ & اختلال برونسازى & \\
\hline
\end{tabular}

$$
\text { r / / • - همبستخى منفى وجود داشت (ه • • (P)). }
$$

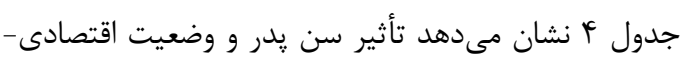

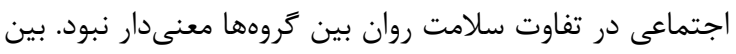

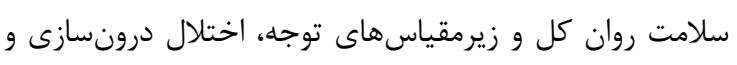

اختلال برونسازى سه كروه تفاوت معنى دار بود (1 (P< (P).

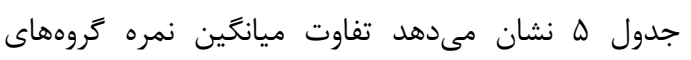
زودرس و عادى در هيجيك از متغيرهاى سلامت روان معنى دار
اختلال برونسازى به ترتيب

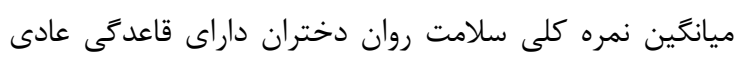

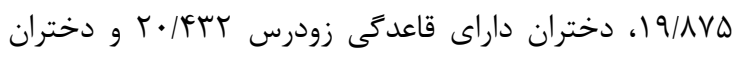

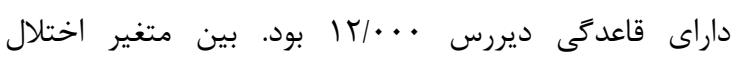

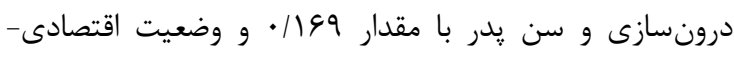

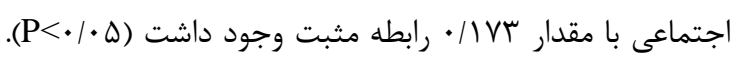

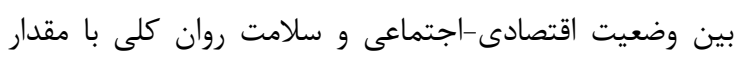

جدول ه: مقايسهاى زوجى ميانگين نمرات متغيرهاى سلامت روان در سه گروه دختران

\begin{tabular}{|c|c|c|c|c|}
\hline $\mathbf{P}$ & انحراف استاندارد & ميانكين تفاوتها & كروههاى مقايسه & متغير ها \\
\hline - IVAT & $1 / 991$ & $\cdot / \Delta \Delta V$ & زودرس-عادى & \multirow{3}{*}{ سلامت روان كل } \\
\hline$\cdot 1 \cdot \cdot 1$ & I/V9V & N/FrY & زودرس -ديررس & \\
\hline$\cdot 1 \cdot \cdot 1$ & $1 / 9 r \Delta$ & $V / \wedge V Q^{* * *}$ & عادى-ديررس & \\
\hline$\cdot 19 \cdot 0$ & $\cdot 10 T 9$ & $\cdot / T V F$ & زودرس-عادى & \multirow{3}{*}{ توجه } \\
\hline$\cdot 1 \cdot \cdot 1$ & $\cdot 1009$ & $1 / 1 / 9^{* * * *}$ & زودرس -ديررس & \\
\hline$\cdot / \cdot r$ & $\cdot 10 \cdot 9$ & $1 / \Delta F Q^{* * *}$ & عادى-ديررس & \\
\hline$\cdot / 499$ & $\cdot / 4 \cdot \Delta$ & - RTH & زودرس-عادى & \multirow{3}{*}{ درونسازى } \\
\hline$\cdot 1 \cdot \cdot 1$ & . /4rq & 1/9rr必 & زودرس-ديررس & \\
\hline$\cdot 1 \cdot \cdot 1$ & $\cdot / r \Lambda \Lambda$ & $1 / 01$. 䄅 & عادى-ديررس & \\
\hline - MFt & $\cdot / 4 \cdot V$ & $-\cdot / r \wedge \Lambda$ & زودرس-عادى & \multirow{3}{*}{ اختلال برونسازى } \\
\hline$\cdot 1 \cdot 11$ & $\cdot|A T|$ & $1 /\left.11\right|^{4 *}$ & زودرس-دير رس & \\
\hline$\cdot 1 \cdot \cdot 1$ & $\cdot / r q$. & $1 / 0 \cdot r^{*}$ & عادى-ديررس & \\
\hline
\end{tabular}


زودرس با خطر بيشتر درونسازى و برونسازى مشكلات روبهرو

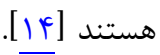

يافتههاى اين مطالعه نشان داد در زيرمقياس اختلال تمركز

و توجه تفاوت مىتواند به اين علت باشد كه دختران دو گرَوه عادى و زودرس بيشتر احساس بىقرارى و خيال يردازى مى كنندو

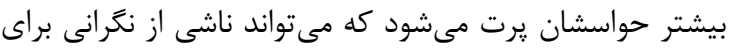

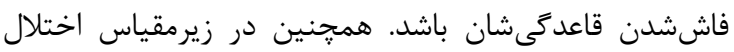

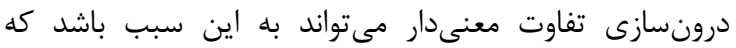
دختران داراى قاعدگى عادى و زودرس بيشتر احسى لحساس غمه، ناميدى و نتخرانى دارند.

در يزوهش Alcala-Herrera و همكاران دختران با قاعدىى دارى زودرس نسبت به همسالان علائم افسردكى بيشترى داشتند

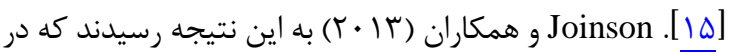

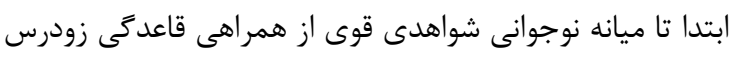

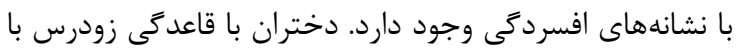

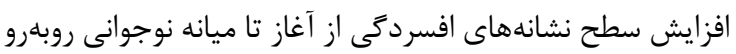

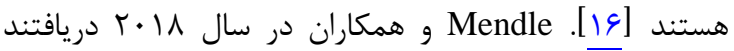
قاعدىى زودرس با نشانهاى افسردگى بيشتر و ر رفتارهاى

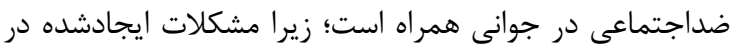

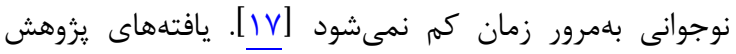
Stice

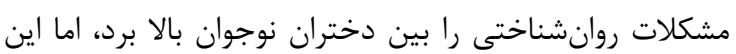

ريسك به ناتوانى مشخصى مرتبط نبود [11].

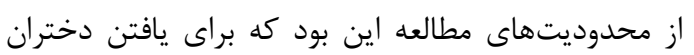

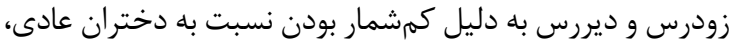

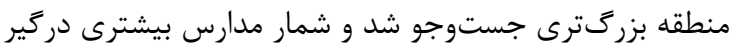

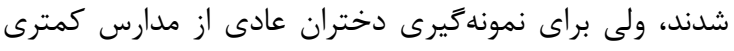
نمونه

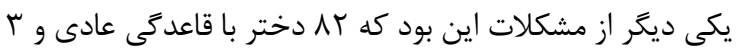

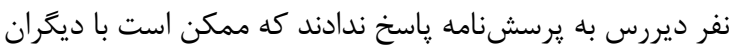

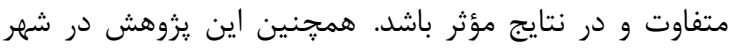
اصفهان انجام شده و نياز است در ديكر نقاط كشور تكرار شود. باسن

\section{نتيجه تَيرى}

يافتهاى اين مطالعه نشان داد بهطوركلى سلامت روان دختران داراى قاعدكى عادى و زودرس به اين دليل كه آنها دهان

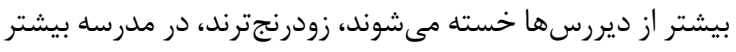

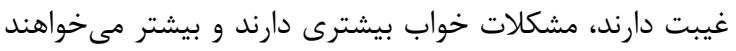

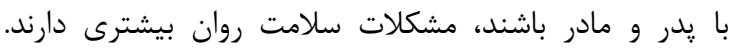

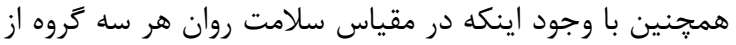

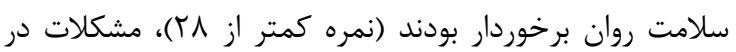
گروه ديررس كمتر بود. به نظر مىرسد زمان شروع قاعدى بـى بر برد

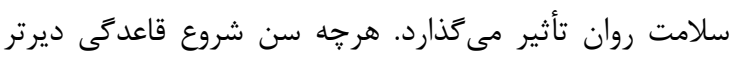
باشد مشكلات در سلامت روان كمتر مىشود.
نبود. تفاوت ميانگين نمره گروههاى زودرس و ديررس و گروههاى عادى و ديررس در متغيرهاى سلامت روان، زيرمقياس اختلال

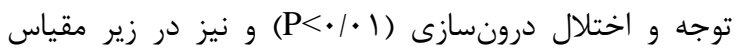
اختلال برونسازى معنى دار بود.

اين مطالعه با هدف مقايسه سلامت روان دختران داراى

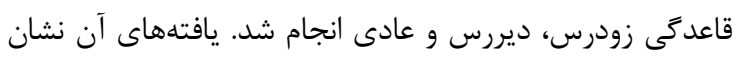

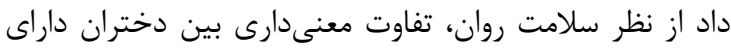

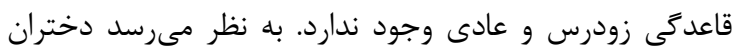

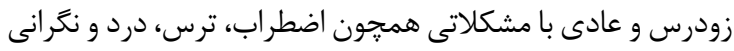

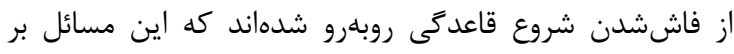

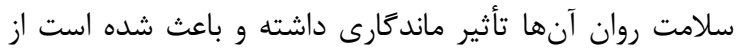

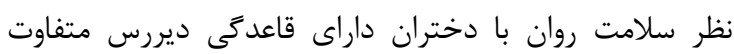

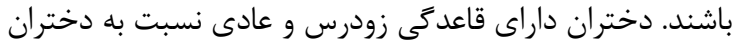

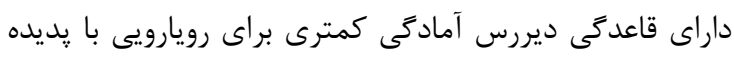

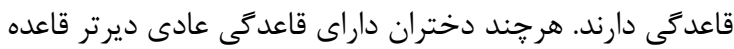

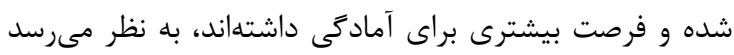

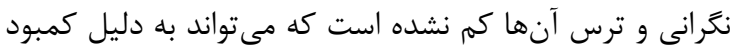

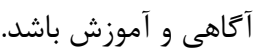

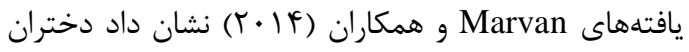

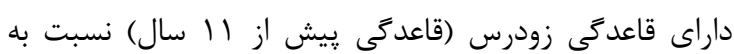

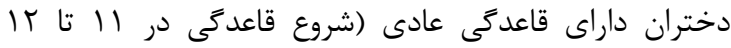

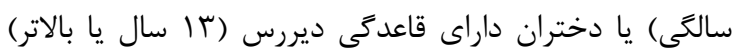

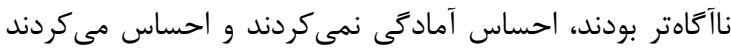

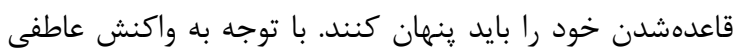

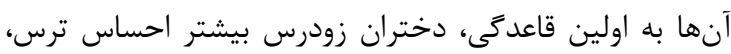

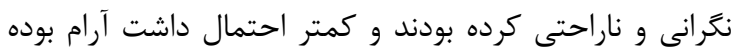

باشند [r]

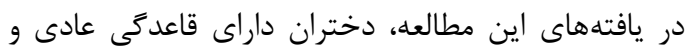

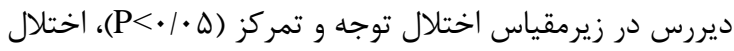

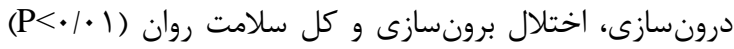

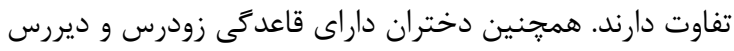

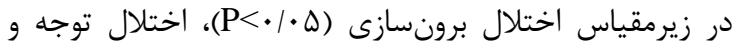

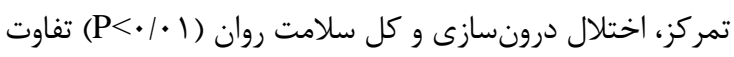

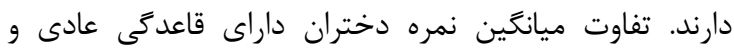

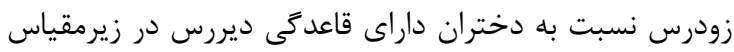

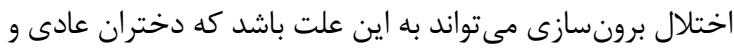

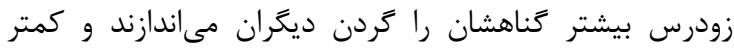

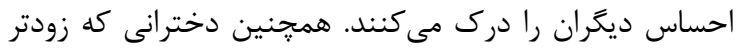

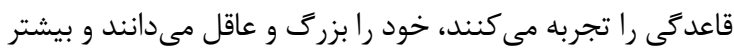

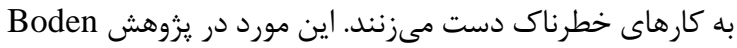

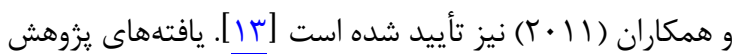
DeRose 


$$
\text { رضايت دانشآموزان و والدين آنها جلب شده است. }
$$

$$
\text { سمهم نو يسنلمكان }
$$

نويسنده اول (يزوهشكر اصلى): مسئول مكاتبات، تدوين

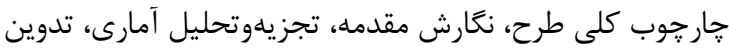

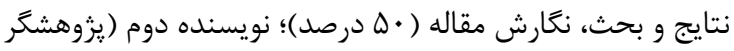

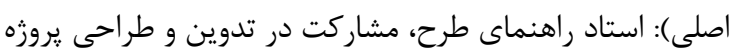
و ويرايش علمى مقاله ( •ه درصد).

$$
\text { حمايت مالى }
$$

\section{REFERENCES}

1. Marvan ML, Chrisler CJ. Menarcheal timing, memories of menarche, and later attitudes toward menstruation. Cogent Psychol. 2018;5(1):1-12. DOI: 10.1080/23311908.2018. 1525840

2. Marvan ML, Alcala-Herrera V. Age at menarche, reactions to menarche and attitudes towards menstruation among mexican adolescent girls. J Pediatr Adolesc Gynecol. 2014; 27(2):61-6. PMID: 24405634 DOI: 10.1016/j.jpag.2013. 06.021

3. Omari O, Abdel Razeq MN, Fooladi MM. Experience of menarche among Jordanian adolescent girls: an interpretive phenomenological analysis. J Pediatr Adolesc Gynecol. 2015;29(3):246-51. PMID: 26463575 DOI: 10.1016/j.jpag. 2015.09.005

4. Remsberg EK, Demerath WE, Schubert C, Chumlea C, Sum SS, Siervogel MR. Early menarche and the development of cardiovascular disease risk factors in adolescent girls: the Fels longitudinal study. J Clin Endocrinol Metab. 2005; 90(5):2718-24. PMID: 15728207 DOI: 10.1210/jc.20041991

5. Bahrami N, Soleimani AM, Chan HY, Ghojazadeh M, Mirmiran P. Menarche age in Iran: a meta-analysis. Iran $J$ Nurs Midwifery Res. 2014;19(5):444-50. PMID: 25400670

6. Salek Ardestani M, Rostampour N, Hashemipour M, Moadab M, Hosseini SM, Hasanzadeh Kashani H, et al. Age of puberty in school-age girls living in Isfahan. J Isfahan Med Sch. 2007;25(86):1-8. [Persian]

7. Moghtaderi N, Refahi Z, Khosravi S. The effect of the life values training on mental health and social development of preschool students. J Psychol Models Methods. 2011; 1(3):61-76.

8. Soltanahmadi Z, Borhani F, Kohan M. The first menstruation experience among student girls. J Qualit Res Health Sci. 2012;1(2):81-91. [Persian]

9. Radoš SN, Bikić ZM, Perić IR. Psychometric properties of the expected/experienced emotions related to menarche scale. 20th Psychology Days in Zadar: Book of Selected

$$
\begin{aligned}
& \text { اين مقاله بركرفته از بخشى از ياياننامه كارشناسى ارشد }
\end{aligned}
$$

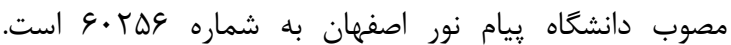

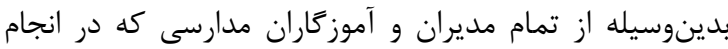

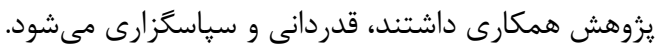

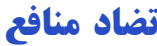

نويسندكان اعلام مىدارند كه هيجزَنه تعارض منافعى

ندارند.

\section{ملاحظات اخلاقى}

اين مطالعه از كميته اخلاق دانشعاه پيام نور با شناسه

Proceedings, Zadar, Croatia; 2017. P. 165-75

10. Stubbs LM. Cultural perceptions and practices around menarche and adolescent menstruation in the United States. Ann N Y Acad Sci. 2008;1135:58-66. PMID: 18574209 DOI: 10.1196/annals. 1429.008

11. Stice E, Presnell K, Bearman KS. Relation of early menarche to depression, eating disorders, substance abuse, and comorbid psychopathology among adolescent girls. Dev Psychol. 2001;37(5):608-19. PMID: 11552757 DOI: 10.1037//0012-1649.37.5.608

12. Tiwari H, Oza UN, Tiwari R. Knowledge, attitudes and beliefs about menarche of adolescent girls in Andand district, Gujarat. East Mediterr Health J. 2006;12(3):428-33. PMID: 17037713

13. Boden MJ, Fergusson MD, Horwood LJ. Age of menarche and psychosocial outcomes in a New Zealand birth cohort. $J$ Am Acad Child Adolesc Psychiatry. 2011;50(2):132-40. PMID: 21241950 DOI: 10.1016/j.jaac.2010.11.007

14. DeRose ML, Shiyko PM, Foster H, Brooks-Gunn J. Associations between menarcheal timing and behavioral developmental trajectories for girls from age 6 to age 15. $J$ Youth Adolesc. 2011;40(10):1329-42. PMID: 21203809 DOI: $10.1007 / \mathrm{s} 10964-010-9625-3$

15. Alcala-Herrera V, Marvan LM. Early menarche, depressive symptoms, and coping strategies. J Adolesc. 2014;37(6): 905-13. PMID: 25019174 DOI: 10.1016/j.adolescence. 2014.06.007

16. Joinson C, Heron J, Araya R, Lewis G. Early menarche and depressive symptoms from adolescence to young adulthood in a UK cohort. J Am Acad Child Adolesc Psychiatry. 2013;52(6):591-8.e2. PMID: 23702448 DOI: 10.1016/ j.jaac.2013.03.018

17. Mendle J, Rayan MR, MnKone MP. Age at menarche, depression, and antisocial behavior in adulthood. Pediatrics. 2018;141(1):e20171703. PMID: 29279324 DOI: 10.1542/ peds.2017-1703 